\title{
¿Cómo aprendemos? Los cuatro pilares con los que la educación puede potenciar los talentos de nuestro cerebro
}

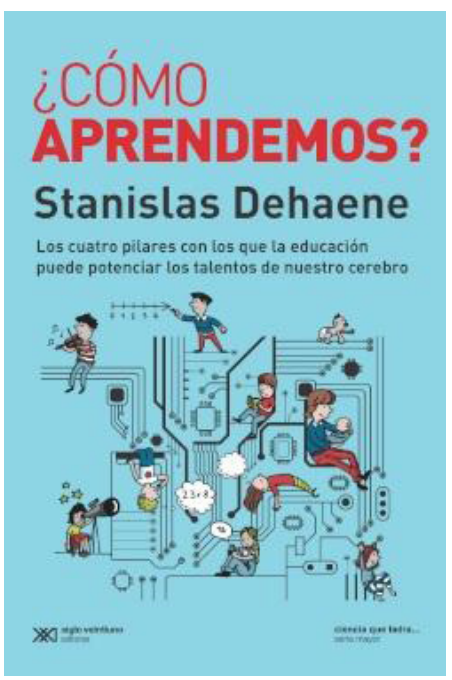

Stanislas Dehaene, 2019.

Buenos Aires: Siglo Veintuno Editores. 350 p p.

¿CÓMO APRENDEMOS? Dehaene

Mtminam

Julieta Fumagalli

Universidad de Buenos Aires / CONICET, Argentina

fumagallijulieta@gmail.com

Trabajo recibido el 31 de enero de 2020 y aprobado el 6 de junio de 2020.

¿Cómo aprende el cerebro? Los cuatro pilares con los que la educación puede potenciar los talentos de nuestro cerebro de Stanislas Dehaene es parte de la Colección Ciencia que ladra, Serie Mayor de la editorial Siglo Veintiuno. El autor cuenta con varios títulos en esta colección de divulgación científica a cargo de científicos y en este nuevo trabajo, publicado en 2019 y traducido al español el mismo año, señala nuevamente la necesidad de vincular el mundo educativo con la investigación científica.

El recorrido propuesto en ¿Cómo aprende el cerebro? está dividido en tres partes enmarcadas por una sección inicial titulada "Introducción a las ciencias del aprendizaje" y una final, “Conclusión”. En las primeras páginas, Dehaene presenta el caso de Felipe, un niño brasileño que a los 4 años fue víctima de una bala perdida y como consecuencia quedó cuadripléjico y ciego. Sin embargo, aunque el niño ha vivido desde el accidente en un hospital, a los 7 años habla a la perfección varias lenguas y crea sus propios cuentos. El autor relata que este encuentro fue el puntapié para comenzar a explorar la capacidad que tiene el cerebro humano de aprender a pesar de la presencia de un trauma grave y le permite hablar de la "extraordinaria resiliencia del cerebro humano" e introducir un concepto central del texto: la plasticidad cerebral.

A su vez, en la sección inicial, el autor se pregunta por qué la evolución inventó el aprendizaje y los seres humanos no nacemos equipados con ciertos conocimientos, como por ejemplo el lenguaje, y propone una serie de interrogantes en torno a la facultad del aprendizaje que se responderá en los siguientes capítulos. Sin embargo, adelanta que no sería posible que nuestro ADN especificara todos los detalles de nuestros conocimientos porque el cerebro humano es resultado de la combinación de información innata que ha sido heredada a lo largo de la evolución y de información proveniente de nuestra experiencia con el medio.

De ese modo, Dehaene desarma la dicotomía entre empirismo e innatismo y presenta un modelo intermedio: el del cerebro bayesiano. Esta propuesta emergente, también conocida como "la teoría del cerebro estadístico", propone que cada niño pequeño es un científico en ciernes que formula, rechaza y selecciona hipótesis para generar teorías del mundo exterior apoyándose en el razonamiento probabilístico. La información genéticamente especificada permite extraer datos del medio y lo innato y lo adquirido se combinan. Como el autor ya lo ha postulado en otros trabajos, el cerebro no es una tabula rasa, sino un dispositivo que aprende y puede reciclar algunas de sus regiones para aprender una nueva habilidad como leer o hacer matemáticas y gracias a la plasticidad puede recuperarse de una lesión cerebral.

En este nuevo libro, el autor se apoyará en los conocimientos que los últimos treinta años de investigación en neurociencias, psicología cognitiva, computación y neurobiología han brindado para saber cómo y por qué aprendemos, qué mecanismos neurofisiológicos están implicados y el rol que la memoria, la atención y el sueño desempeñan en el aprendizaje. 
La primera parte se compone de dos capítulos en los que el autor ofrece un recorrido por distintas teorías que explican el proceso de aprendizaje y los avances de la inteligencia artificial en el diseño de modelos de aprendizaje. En el capítulo 1, "Siete definiciones del aprendizaje”, responde la pregunta que da nombre a la sección y sostiene que aprender implica construir modelos internos tanto del mundo exterior como de la realidad interna. El autor expone que, con base en un modelo jerárquico que involucra diferentes niveles, los sistemas sensoriales y determinadas áreas del cerebro se encargan de captar regularidades cada vez más complejas en los objetos y los conceptos. De este modo, el cerebro aloja modelos mentales de la lengua del entorno, de los objetos y también del cuerpo y de los gestos necesarios para coordinar distintas acciones con un objetivo específico como puede ser tomar un lápiz o tocar un instrumento. En relación con los algoritmos informáticos de aprendizaje, Dehaene detalla que las redes de neuronas artificiales toman como modelo la organización jerárquica de la corteza cerebral $y$, con base en capas sucesivas, intentan descubrir regularidades cada vez más profundas y abstractas en relación con el input que reciben.

En el capítulo 2, “¿Por qué nuestro cerebro aprende mejor que las máquinas actuales?”, el autor sostiene que los avances del machine learning de los últimos treinta años permitieron descubrir numerosos aspectos que facilitan el aprendizaje, pero las máquinas aún no logran superar el aprendizaje y la inteligencia humana. Para demostrarlo, enumera algunas de las funciones que los niños pequeños poseen, pero las redes de neuronas artificiales no. Entre estas diferencias especifica que las redes aprenden todo a un mismo nivel, mientras el cerebro humano es más flexible, jerarquiza la información y logra extraer principios generales, lógicos y explícitos que permiten generar modelos abstractos. En este capítulo, el autor brinda ejemplos que muestran que esta capacidad de abstracción está involucrada en distintos procesos de aprendizaje.

La segunda parte, “Cómo aprende nuestro cerebro”, está compuesta por cuatro capítulos en los que Dehaene retoma el debate entre lo innato y lo adquirido. En el capítulo 3, "El saber invisible: las sorprendentes intuiciones de los bebés", el autor vuelve a postular que es falso pensar al cerebro de los bebés como una tábula rasa y resalta que gracias a los avances metodológicos de las ciencias cognitivas se ha demostrado que los recién nacidos poseen un amplio repertorio de capacidades. El autor aporta distintas evidencias del alcance de conocimientos innatos de los bebés, entre ellos el conocimiento de los objetos, de los animales y las personas, del número y la probabilidad, la percepción de rostros y el lenguaje.

En el capítulo 4, “El nacimiento del cerebro", Dehaene presenta evidencias de estudios realizados con imágenes cerebrales que han permitido determinar que el cerebro del bebé se encuentra organizado desde el nacimiento. El autor explica que esta arquitectura es producto de la dotación genética de los seres humanos dado que durante la gestación la corteza cerebral se organiza, conecta y pliega para determinar regiones y subdividirlas en módulos específicos. Sin embargo, se encarga de dejar en claro que no niega las diferencias individuales y que el medio también tiene su participación.

En el capítulo 5, “Lo que adquirimos”, Dehaene retoma la idea de que el cerebro humano es el resultado de la interacción entre la información innata y la del entorno. Postula que la organización innata con la que viene equipado el cerebro de los bebés rápidamente cambiará a partir de la interacción con el medio, las experiencias y el aprendizaje. En este capítulo el autor se apoya en las evidencias que brindan los distintos avances tecnológicos y científicos actuales para demostrar cómo el aprendizaje genera, modifica y recicla circuitos y regiones del cerebro a partir de una descripción de las neuronas y los procesos físicos y químicos implicados en la sinapsis. Estos datos le permiten afirmar que la plasticidad de la sinapsis es la responsable del aprendizaje y que cada vez que aprendemos hay modificaciones que se reflejan en la anatomía del cerebro.

En este capítulo profundiza sobre la plasticidad cerebral y presenta distintos ejemplos de los factores que intervienen en este proceso. A su vez, hace referencia a otro concepto relevante al hablar de desarrollo y aprendizaje: el "período sensible". Dehaene subraya que este período durante el cual la plasticidad es máxima se extiende durante varios años y varía según la región porque la sobreproducción sináptica no se da en todas las áreas del cerebro de manera simultánea. Asimismo, advierte que si bien la capacidad de aprendizaje se reduce luego de la primera infancia ( 3 años), no desaparece y hace hincapié en la importancia de la intervención pedagógica temprana e intensiva.

En el capítulo 6, "Reciclen su cerebro", el autor se centra en el rol de la educación en el desarrollo temprano del cerebro e introduce la hipótesis de reciclaje neuronal. Esta hipótesis propone una explicación sobre la adquisición de constructos culturales y sus bases cerebrales. Para desarrollarla, vuelve 
sobre aspectos presentados en otros capítulos. Por un lado, retoma la propuesta del enfoque del cerebro estadístico y, por otro, reitera que al nacer el cerebro presenta la arquitectura heredada de la evolución y distintas áreas corticales especializadas. Postula que el aprendizaje se apoya en una o varias de estas áreas corticales preestablecidas que se modificarán a partir de la plasticidad sináptica asociada al aprendizaje. A su vez, dice que cada objeto cultural que se aprende, el alfabeto o los símbolos numéricos, debe encontrar circuitos corticales preestablecidos que estén destinados a una función similar. Por lo tanto, estos aprendizajes se pueden fijar en el cerebro porque existen circuitos apropiados que solamente deben reorientar su función.

En la tercera parte, “Los cuatro pilares del aprendizaje”, el autor va más allá de la plasticidad cerebral para explicar cómo los seres humanos han logrado explotar la capacidad de aprender. Para esto, aborda una serie de funciones desarrolladas a lo largo de la evolución que sirven de soporte para el aprendizaje.

En el capítulo 7, “La atención”, el autor expone que el cerebro recibe una gran cantidad de estímulos provenientes de los sentidos de la vista, tacto y olfato que inicialmente procesa en paralelo. Sin embargo, los recursos del cerebro no son suficientes para tratarlos a todos con la misma profundidad y es necesario que la atención entre en acción y seleccione una porción de información para que los recursos se concentren en ese aspecto en particular. La selección de información relevante es fundamental para el aprendizaje, por eso es importante que los niños aprendan a prestar atención. En este capítulo, el autor también resalta que es primordial que los docentes logren canalizar la atención de los estudiantes de manera exitosa, ya que solamente aquello que esté en el foco de atención de los niños se representará con la potencia necesaria para que el aprendizaje se pueda llevar adelante.

En el capítulo 8, "El compromiso activo", Dehaene brinda diferentes ejemplos y relata investigaciones de diversos campos para describir qué es y cómo funciona este segundo pilar del aprendizaje. Este se encuentra estrechamente relacionado con la motivación, porque para aprender es necesaria una actitud comprometida, activa y atenta, así como contar con objetivos claros. La presentación de experiencias en las que se comparan situaciones de aprendizaje en el aula que siguen el modelo de clase magistral y propuestas que proponen una interacción activa con materiales estimulantes, actividades prácticas, discusiones en grupos, etcétera, le sirven al autor para demostrar que los aprendices progresan más en las modalidades de enseñanza que promueven el compromiso activo. Sin embargo, distingue las propuestas pedagógicas en las que el estudiante participa activa y atentamente del aprendizaje y se apoyan en el principio de compromiso activo de los métodos de aprendizaje por descubrimiento y del constructivismo clásico.

En el capítulo 9, "El error es productivo y dar un buen feedback es garantía de mejores aprendizajes", el autor analiza el papel que cumple la detección y corrección de los errores en el proceso de aprendizaje y afirma que el error es fundamental para aprender porque cuando se detectan errores, el cerebro puede corregir sus modelos del mundo. En este capítulo, también se refiere a la calificación y postula que, si una nota no es acompañada de comentarios detallados, no constituye un feedback eficaz y funciona como una sanción, lo que puede generar efectos negativos sobre los sistemas emocionales del cerebro y desencadenar una baja autoestima en el estudiante y, en consecuencia, interferir en el proceso de aprendizaje. A su vez, en relación con el error, plantea que es necesario sacar ventajas del efecto que el procesamiento de los errores tiene en el aprendizaje y afirma que la alternancia entre estudio y evaluación genera efectos positivos en el aprendizaje a largo plazo.

En el capítulo 10, “La consolidación”, Dehaene brinda ejemplos para demostrar que al principio todos los aprendizajes requieren grandes esfuerzos y esto se refleja a nivel cortical, ya que durante la realización de la tarea se activan regiones asociadas a la atención ejecutiva y espacial. Nuevamente, evidencias de estudios con imágenes le permiten mostrar cómo, a partir de la práctica intensiva, el aprendizaje se automatiza y comienzan a activarse los circuitos especializados y se liberan recursos atencionales para destinarlos a otras tareas.

El autor resalta que el sueño cumple un papel fundamental en la consolidación de los aprendizajes porque los conocimientos que se adquirieron en la jornada anterior, gracias a la actividad neuronal nocturna, se recodifican en un formato abstracto que permite la generalización y automatización. Los datos que presenta en el capítulo indican que la consolidación nocturna trabaja desde los primeros meses de vida y los intervalos vigilia-sueño son un factor relevante para aprender y generalizar mejor. Por lo tanto, mejorar la calidad y duración del sueño durante la infancia y la adolescencia tendrá un efecto positivo en el rendimiento escolar.

¿Cómo aprende el cerebro? cierra con un capítulo final, “Conclusión”, en el que Dehaene resume los aspectos 
centrales que explican el modo en el que aprende el cerebro y ofrece trece recomendaciones basadas en los resultados científicos que expuso a lo largo de los distintos capítulos. Finalmente, destaca que las investigaciones realizadas en el campo de las neurociencias tienen mucho para ofrecer a la educación y que conocer esta información permitirá fomentar el aprendizaje de los niños.
En ¿Cómo aprende el cerebro? los docentes de los distintos niveles, estudiantes de profesorado y profesionales de distintas disciplinas encontrarán un material con información relevante y evidencias científicas actualizadas sobre cómo operan los distintos aprendizajes en el cerebro de los niños, cómo se modifican, generan y reciclan circuitos para aprender y cuáles son los aspectos centrales en los que debería apoyarse la enseñanza y la intervención para facilitar y potenciar tales procesos. 